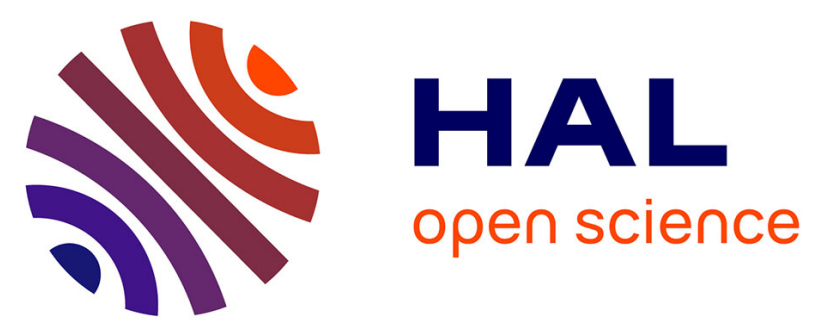

\title{
Effects of varying thinning regimes on carbon uptake, total stem wood growth, and timber production in Norway spruce (Picea abies) stands in southern Finland under the changing climate
}

\author{
Ge, Kellomäki, Peltola, Zhou, Wang, Väisänen
}

\section{To cite this version:}

Ge, Kellomäki, Peltola, Zhou, Wang, et al.. Effects of varying thinning regimes on carbon uptake, total stem wood growth, and timber production in Norway spruce (Picea abies) stands in southern Finland under the changing climate. Annals of Forest Science, 2011, 68 (2), pp.371-383. 10.1007/s13595-0110025-y . hal-00930760

\author{
HAL Id: hal-00930760 \\ https://hal.science/hal-00930760
}

Submitted on 1 Jan 2011

HAL is a multi-disciplinary open access archive for the deposit and dissemination of scientific research documents, whether they are published or not. The documents may come from teaching and research institutions in France or abroad, or from public or private research centers.
L'archive ouverte pluridisciplinaire HAL, est destinée au dépôt et à la diffusion de documents scientifiques de niveau recherche, publiés ou non, émanant des établissements d'enseignement et de recherche français ou étrangers, des laboratoires publics ou privés. 


\title{
Effects of varying thinning regimes on carbon uptake, total stem wood growth, and timber production in Norway spruce (Picea abies) stands in southern Finland under the changing climate
}

\author{
Zhen-Ming Ge • Seppo Kellomäki • Heli Peltola • \\ Xiao Zhou • Kai-Yun Wang • Hannu Väisänen \\ Received: 29 December 2009 / Accepted: 13 June 2010/Published online: 15 February 2011 \\ (C) INRA and Springer Science+Business Media B.V. 2011
}

\begin{abstract}
- Introduction Based on previous studies, it is assumed that the growth of Norway spruce (Picea abies) in southern Finland $\left(61^{\circ} \mathrm{N}\right)$ may decrease under the changing climate due to the increasing soil water deficit, without management.

- Materials and methods A process-based ecosystem model was employed to study how varying thinning scenarios (nine different plus one unthinned) may affect the net carbon uptake, total stem wood growth, and timber production in Norway spruce stands on three sites with varying soil water availability under the changing climate.

- Results and discussion We found that the carbon uptake and total stem wood growth were lower due to reduced soil moisture. This was especially the case on the site with low water moisture if no thinning was applied. Thinning increased the amount of water infiltrating into the soil profile, as well as the availability of soil water, regardless of the site. The current thinning guidelines (BT $(0,0))$ may need to be modified under the changing climate for Norway spruce, especially on sites with poor soil water conditions. On these sites, the thinning scenarios with frequent thinning could simultaneously help to increase the growth rate of
\end{abstract}

Handling Editor: Erwin Dreyer

Z.-M. Ge $(\triangle) \cdot$ S. Kellomäki $\cdot$ H. Peltola $\cdot$ X. Zhou

K.-Y. Wang $\cdot H$. Väisänen

School of Forest Sciences, University of Eastern Finland,

Yliopistokatu 7, P.O. Box 111, 80101, Joensuu, Finland

e-mail: zhenming.ge@uef.fi

Z.-M. Ge $\cdot$ K.-Y. Wang

Shanghai Key Laboratory of Urbanization

and Ecological Restoration, East China Normal University,

Shanghai 200062, China trees and to mitigate the negative impacts of increasing soil water deficit on tree growth. On the sites with high soil water availability, the thinning scenarios with moderate intensive thinning or with delayed first thinning may simultaneously provide higher timber yield and carbon stock than if the current thinning recommendations are applied.

Keywords Ecosystem model . Climate change. Management · Forest productivity - Picea abies . Boreal zone

\section{Introduction}

In the boreal forests of Finland the growth of Norway spruce (Picea abies) is greatly limited by low summer temperatures and a short growing season, additionally, a shortage of water may also affect its productivity (Bergh et al. 1999, 2005). The water shortage implies a pronounced reduction in stomatal conductance in response to the deficit of soil water in the growing season ( $\mathrm{Lu}$ et al. 1995, 1996; Cienciala et al. 1998), with a consequent reduction in carbon uptake and stem wood growth (Phillips et al. 2001).

In Finland, the annual mean temperature is expected to increase by $2-7^{\circ} \mathrm{C}$ by the end of this century due to the global climate change (Carter et al. 2005; Ruosteenoja et al. 2005). The increase is likely to be more pronounced in wintertime, though higher temperatures are also expected in summertime. At the same time, the annual precipitation may increase by $6-37 \%$, again with the increase being the more salient in wintertime, while in the summertime it may remain the same or even decrease locally compared to the 
current climate (Carter et al. 2005; Ruosteenoja et al. 2005). These changes in temperature and precipitation, along with the increase in the atmospheric $\mathrm{CO}_{2}$, may profoundly affect stem wood growth and productivity of Norway spruce in Finland (Kellomäki et al. 2008a).

In addition to climatic conditions, forest management, such as thinnings, affects the carbon fixation rate in the forest ecosystems, as well as the growth and dynamics of forests (Thornley and Cannell 2000). In thinning, the stand density is reduced to increase the availability of radiation, water, and nutrients for the remaining trees. On the other hand, due to the effects of climate change on water and nutrient cycles, as well as the carbon uptake, the sensitivity of the forest growth and productivity to thinning may be different from that under the current climate. It is assumed that under the changing climate the growth of Norway spruce may even be reduced in the boreal conditions on sites with low water holding capacity, especially if its management is not adapted to the changing climatic conditions (Kellomäki et al. 2008b). However, little is known about the likely impacts of the concurrent change in climate and management on the growth and dynamics of forest stands, with few studies existing in this respect for boreal conditions (e.g., Mäkelä et al. 2000; Matala et al. 2005; Kellomäki et al. 2008b).

Previous studies on the long-term growth and dynamics of boreal forests are mostly based on statistical growth and yield models (e.g., Hynynen et al. 2002), which utilize, in their parameterization and validation, inventory data representing past management and climatic conditions. Thus, their predictions for the changing climate may be biased, although they could be of benefit regarding the decision making for management under the current climate (Matala et al. 2005). However, for the prediction of forest productivity under the changing climate and management, process-based models should be preferred because they could predict the growth and dynamics of forests based on physiological processes driven by hydrological and nutrient cycles and climatic factors (Mäkelä et al. 2000).

This study is implemented under the assumption that the growth of Norway spruce may be reduced under the changing climate and that the impact is dependent on the thinning scenarios used over the rotation, as well as site conditions. In this context, a process-based ecosystem model (FinnFor) was employed to determine how varying thinning scenarios may affect net carbon uptake, total growth of stem wood, and timber production but also the availability of soil water. The simulations represent Norway spruce stands on three sites with varying soil water moisture under the changing climate in southern Finland $\left(61^{\circ} \mathrm{N}\right)$. Altogether, ten different management scenarios including one with no thinning and nine with varying thinning were used in the simulations, which were extended over a 100 -year period.

\section{Material and methods}

2.1 Main principles of ecosystem model and simulations

Outline The study uses a process-based ecosystem model (FinnFor) developed by Kellomäki and Väisänen (1997). Figure 1 shows that in the model the forest productivity and net carbon uptake $\left(P_{\mathrm{n}}\right)$ is dependent on temperature $(T)$, atmospheric $\mathrm{CO}_{2}\left(C_{\mathrm{a}}\right)$, precipitation $(P)$, nitrogen supply $(N)$, and net radiation $\left(R_{\mathrm{n}}\right)$, but also on canopy stomatal conductance $\left(g_{\mathrm{cs}}\right)$ and tree respiration $(R)$. In the model, dynamics of the foliage area $(L)$ controls the interception of water and radiation in the canopy. Litter fall transfers nitrogen from the trees to the soil, where nitrogen is made available through the decomposition of litter and humus. In the simulations, the key question is how thinning (timing, intensity) will affect the $L$ and its recovery after thinning, with the consequent effects on the net ecosystem productivity of the remaining trees.

Calculation of carbon uptake The physiological core of the model is the biochemical model for photosynthesis developed by Farquhar et al. (1980). The rate of gross photosynthesis is linked to the climatic variables (radiation, air temperature, air humidity, $\mathrm{CO}_{2}$ ) and soil variables (temperature, availability of water, and nitrogen) and calculated on an hourly basis. Seasonality between active and dormant periods controls the sensitivity of photosynthetic response to the environmental factors (Hänninen and Hari 2002). Respiration losses include day, maintenance, and growth respirations. The remaining amount of photosynthesis (net photosynthesis) is converted to the growth of foliage, branches, coarse roots, fine roots, and stem.

Photosynthesis is calculated per unit leaf area and thereafter scaled up to canopy photosynthesis per unit ground area. This uses an integrated sun/shade sub-model, which considers the daily change in the fraction of sunlit $\left(L_{\text {sun }}\right)$ and shaded leaves $\left(L_{\mathrm{sh}}\right)$ within the canopy and the difference in leaf photosynthesis and sunlit/shaded leaves stomatal conductance ( $g_{\text {cs.sun }}$ and $\left.g_{\text {cs.sh }}\right)$, respectively. The values of parameters in the photosynthetic model are related to the leaf nitrogen $\left(N_{\mathrm{L}}\right)$, which is reduced as canopy depth increases (Kellomäki and Wang 1997). The calculations for net canopy photosynthesis $\left(P_{\mathrm{nc}}\right)$ accounts separately for the contribution of sunlit $\left(P_{\mathrm{nc} . \text { sun }}\right)$ and shaded leaf $\left(P_{\text {nc.sh }}\right)$ fractions.

$$
\begin{aligned}
P_{\mathrm{nc}}= & P_{\text {nc.sun }}+P_{\text {nc.sh }} \\
= & \int_{0}^{L} f\left(R_{\text {nc.sun }}\right) f(T) f\left(C_{\mathrm{a}}\right) f\left(N_{\mathrm{L}}\right) f\left(L_{\text {sun }}\right) f\left(g_{\text {cs.sun }}\right) d L \\
& +\int_{0}^{L} f\left(R_{\text {nc.sh }}\right) f(T) f\left(C_{\mathrm{a}}\right) f\left(N_{\mathrm{L}}\right) f\left(L_{\mathrm{sh}}\right) f\left(g_{\text {cs.sh }}\right) d L
\end{aligned}
$$


Fig. 1 Main framework of FinnFor model used in this study. $P_{\mathrm{n}}$ net carbon uptake, $L$ foliage area, $T$ temperature, $C_{\text {a }}$ atmospheric $\mathrm{CO}_{2}, P$ precipitation, $N$ nitrogen supply, $R_{\mathrm{n}}$ net radiation, $g_{\text {cs }}$ canopy stomatal conductance, $R$ tree respiration

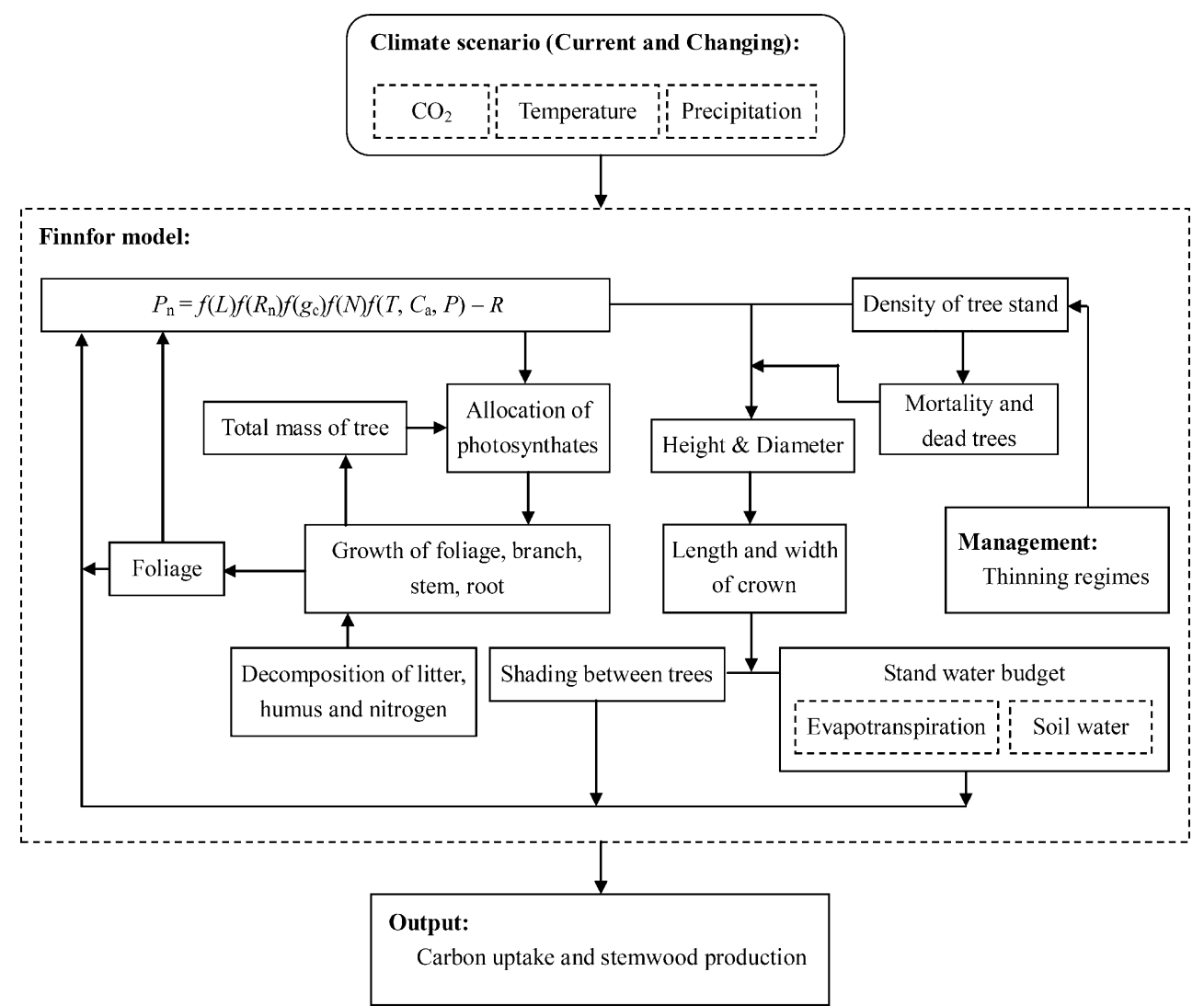

Water depletion Depletion of water is calculated hourly on the basis of total evapotranspiration, which is the sum of transpiration from trees and the evaporation from wet surfaces of the canopy and evaporation from the ground surface. A "big leaf" model (Kellomäki and Wang 1999, 2000 ) is used to calculate transpiration (whole tree level) by considering that transpiration depends on the cumulative effects of total leaf area and the conductance of single leaves (Kellomäki and Wang 1999, 2000). Evaporation from the wet canopy is derived from the water pool intercepted on the foliage surface. The Penman-Monteith equation is used to compute the transpiration and canopy surface evaporation on the basis of the net radiation interception, aerodynamic resistances, and the boundary layer resistance of canopy at the mean canopy height and reference height (Monteith and Unsworth 1990). Calculation of the evaporation from the ground surface is based on an iterative solution of the energy balance (Jansson 1991a, b), using the Penman combination equation with the variable ground surface net radiation, aerodynamic resistance, and soil surface resistance (Monteith and Unsworth 1990).

Soil water flow Soil surface, organic soil layer, and mineral soil layer constitute the layered structure of the soil profile (Jansson 1991a, b). The amount of water in the soil surface pool is calculated based on the incoming (throughfall) and outgoing water flows (runoff from the surface pool, infiltration from the surface pool to soil profile, and ground surface evaporation; Kellomäki and Väisänen 1996, 1997). The year-round calculations included the snow accumulation, which is a function of snowfall and the melting-freezing dynamics (Kellomäki and Väisänen 1996, 1997).

Water/heat condition in the mineral soil is calculated for the layers of soil profile as adopted from Jansson (1991a, b). Darcy's law and Euler integration are used in the calculations. The soil profile, $1 \mathrm{~m}$ deep, was divided into 11 layers, which were horizontally homogenous. The impact of the soil water on forest growth is introduced into the simulations through the relative availability of water in the rooting zone (extractable water for trees), which is used to calculate the soil water deficit ( $W_{\mathrm{d}}$; Granier et al. 1999).

$W_{\mathrm{d}}=\left[0.4\left(W_{\mathrm{x}}-W_{\mathrm{w}}\right)-\left(W_{\text {Soil }}-W_{\mathrm{w}}\right)\right]$

where $W_{\mathrm{x}}$ is the threshold of volumetric water content at the field capacity, $W_{\mathrm{w}}$ is the volumetric water content at the wilting point, and $W_{\text {Soil }}$ is the volumetric water content in the rooting zone.

Decomposition of litter and humus The algorithm developed and parameterized by Chertov and Komarov (1997) is used in the model to calculate the decomposition of litter 
(dead organic material from any compartment of trees) and humus (soil organic matter). The decomposition rate of different types of litter and soil organic matter is determined by soil temperature and moisture, as well as nitrogen and ash content of the litter. Litter moisture is a linear function of the moisture in the uppermost layer of the soil profile. Nitrogen is released through decomposition, but a part of it is immobilized in the mineral topsoil which is a function of the carbon/nitrogen ratio in the humus. The atmospheric deposition of nitrogen is included in the soil sub-model.

Properties of initial tree population and growth and dynamics of tree stands The initial tree population is divided into cohorts representing trees of the same size. Each cohort is defined by the tree species, the number of trees per hectare, diameter at breast height $(\mathrm{DBH}$, height $\geq$ $1.3 \mathrm{~m}$, or stump height if the tree height $<1.3 \mathrm{~m}$ ), height, and age. These variables are used to initialize the model simulations. The values of dimensions of the trees (diameter, height, and stem volume, biomass of foliage, branches, coarse and fine roots) are updated annually. First, the total annual net photosynthesis is allocated to the biomass growth of different tree organs (foliage, branches, stem, coarse and fine roots) following the allometric growth between organs (Marklund 1987). Photosynthates allocated to the stem are converted to the volume growth of stem wood $\left(V_{\mathrm{s}}\right)$ applying:

$V_{\mathrm{s}}=V_{\text {Initial }}+\int_{0}^{t} a \frac{P_{\text {mass }}(t)}{\rho}$

where $V_{\text {Initial }}$ is the initial stocking, $P_{\text {mass }}(t)$ is the annual net photosynthesis available for growth of stem wood in the year $t$ and $\rho$ is the wood density, $a$ is a parameter. Diameter and height of trees are calculated with the help of empirical equations developed by Marklund (1987).

Mortality The mortality rate is updated every 5 years based on the model developed by Hynynen et al. (2002), who applied the mortality model of Reineke (1933). At the beginning of each simulation step, the probability of the survival of trees in each cohort is calculated with regard to the stocking in the stand, the position of the trees in the stand, and the lifespan of the trees. At the end of each simulation step, the stocking of stem wood in the whole tree population is compared with the self-thinning threshold, which determines the maximum allowable stocking per unit area. If the threshold has been reached, mortality is triggered, and the number of trees is reduced in each tree cohort to the level allowed by Reineke's model with the parameter values specific for Norway spruce (Hynynen et al. 2002).
Thinning Thinning is based on the reduction of the basal area, which is converted into the number of trees $(\mathrm{PF}(i))$ to be removed from each diameter class $i$.

$\mathrm{PF}(i)=\mathrm{VJ} \times \mathrm{RL}(i) \times\left(\frac{\overline{\mathrm{DBH}}}{\mathrm{DBH}(i)}\right)^{\mathrm{HT}}$

where $\mathrm{VJ}$ is a factor to balance the basal area after thinning to that defined by the thinning rate, $\mathrm{RL}(i)$ the number of trees in the diameter class $i, \overline{\mathrm{DBH}}$ the mean diameter for trees in the stand weighted with the basal area before thinning, and DBH (i) is the diameter in the class $i$. The power exponent HT defines the thinning pattern and the relative reduction in the number of trees in the diameter classes.

\subsection{Validation and application of the model}

The validation and performance of the model has been discussed in several previous papers, in regard to: (a) model calibration of hourly photosynthetic rate and stomatal behavior (Medlyn et al. 2001, 2002), (b) model computations on the influence of the interrelationship between soil moisture and forest productivity in the boreal conditions (Kellomäki and Väisänen 1996), (c) model calculations regarding the exchange of $\mathrm{CO}_{2}$ and $\mathrm{H}_{2} \mathrm{O}$ between the atmosphere and the conifer stand under boreal conditions (Kellomäki and Wang 1999, 2000), (d) model validation against growth and yield tables and measurements of the growth history of trees in thinning experiments (Matala et al. 2003), and (e) sensitivity analysis of the growth of Norway spruce in regard to the changes in temperature, precipitation, atmospheric $\mathrm{CO}_{2}$ concentration, and nitrogen content of foliage (Briceño-Elizondo et al. 2006).

This study also investigated the performance of the model by contrasting the predicted growth against the correspondingly measured growth for the permanent sample plots of the Finnish National Forest Inventory (NFI). In these calculations, 88 Norway spruce plots covering the 13 Forests Centers throughout Finland $\left(60-70^{\circ} \mathrm{N}\right.$, see Fig. 3), with the growth measurements available for the period 1985-1995, were utilized. A clear correlation existed between the simulated and measured growth values (Fig. 2, left panel), without systematic deviation between them. Furthermore, the growth prediction of the FinnFor model is also in line with a corresponding prediction of the statistical growth and yield model (Motti) in thinned Norway spruce stands under the current climatic conditions (Fig. 2, right panel).

\subsection{Layout for the simulations and data analyses}

Study sites For this study, three young stands of Norway spruce, with a similar stand structure, were selected from 


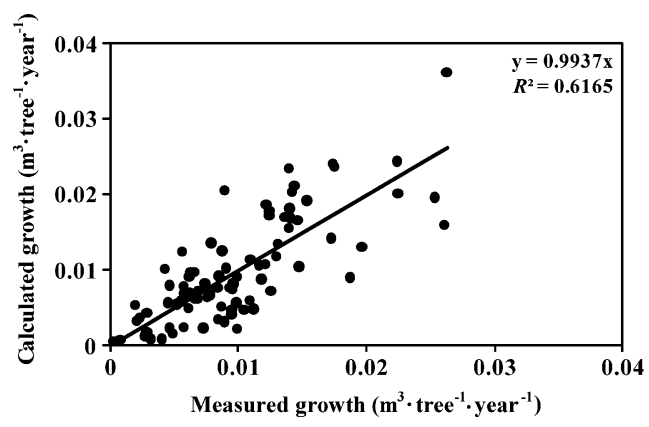

Fig. 2 Left Relationship between the measured (NFI, $n=88$ plots) and simulated (FinnFor) stem volume growth of Norway spruce for forest inventory plots throughout Finland $\left(60-70^{\circ} \mathrm{N}\right)$. Right Stem volume of

the NFI database for 1999-2000 (Fig. 3), on the west-toeast direction in southern Finland with the same latitude $\left(61^{\circ} \mathrm{N}\right)$. They occupied medium fertile (Myrtillus) to fertile sites (Oxalis-Myrtillus; Cajander 1949). The initial conditions of the stands were described in terms of the diameter, height and number of trees per cohort, and the sites were characterized by the location, site type, mean volumetric water content of the topsoil $(30 \mathrm{~cm})$, and thickness of litter and humus (Table 1). The sites represented different initial soil moisture conditions, i.e., site $S_{\mathrm{H}}$ represented the highest, site $S_{\mathrm{M}}$ the medium, and site $S_{\mathrm{L}}$ the lowest soil moisture content based on Vehviläinen and Huttunen (2002). The initial mass of organic matter in the soil was $68 \mathrm{Mg} \mathrm{ha}^{-1}$ for sites $S_{\mathrm{H}}$ and $S_{\mathrm{M}}$ and $70 \mathrm{Mg} \mathrm{ha}^{-1}$ for site $S_{\mathrm{L}}$.

Climate scenario The climate and weather inputs represented two scenarios for the period 2000-2099, i.e., one for the current climate (Cur) and another for the changing climate (CC). The spatial resolution of the grid for the current climate was $10 \times 10 \mathrm{~km}$, while for the changing climate scenario it was $50 \times 50 \mathrm{~km}$ (Carter et al. 2005; Ruosteenoja et al. 2005). The different resolution (grid size) for these data is dependent on the number of weather stations supplying the most reliable datasets for the scenario analyses. In the simulations, the calculation algorithm used the climate for the closest grid point for the climate data of the sample plot.

The current climate represents the mean data for the period 1970-2000 repeated over the 100-year simulation period, with a constant $\mathrm{CO}_{2}$ concentration of $352 \mathrm{ppm}$ (mean for the period 1970-2000). The scenario used for the climate change was originally compiled by the Finnish Environmental Institute (SYKE) and the Finnish Meteorological Institute (FMI) for the FINADAPT project (Carter et al. 2005; Ruosteenoja et al. 2005).

During the period 2000-2099, the annual mean temperature is projected to increase by up to $4^{\circ} \mathrm{C}$ in the summer and more than $6^{\circ} \mathrm{C}$ in the winter, while the atmospheric

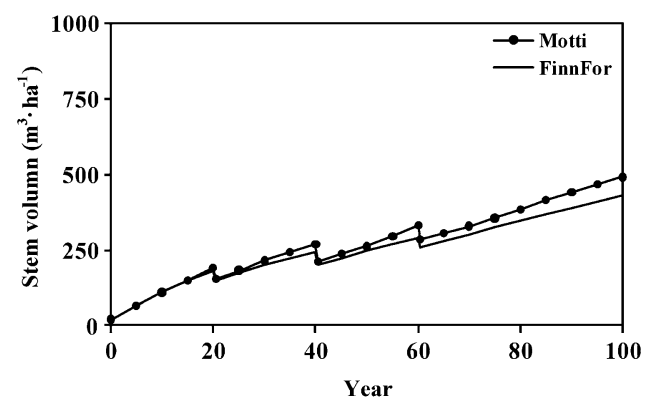

managed Norway spruce stands ( $n=47$ plots) simulated using the Motti and FinnFor models (see Matala et al. 2005)

concentration of $\mathrm{CO}_{2}$ is expected to increase from the value $352 \mathrm{ppm}$ (mean for the period 1970-2000) to $840 \mathrm{ppm}$ in the year 2099. In the southern area, covering our study sites, the average precipitation will increase by $15 \%$, mainly

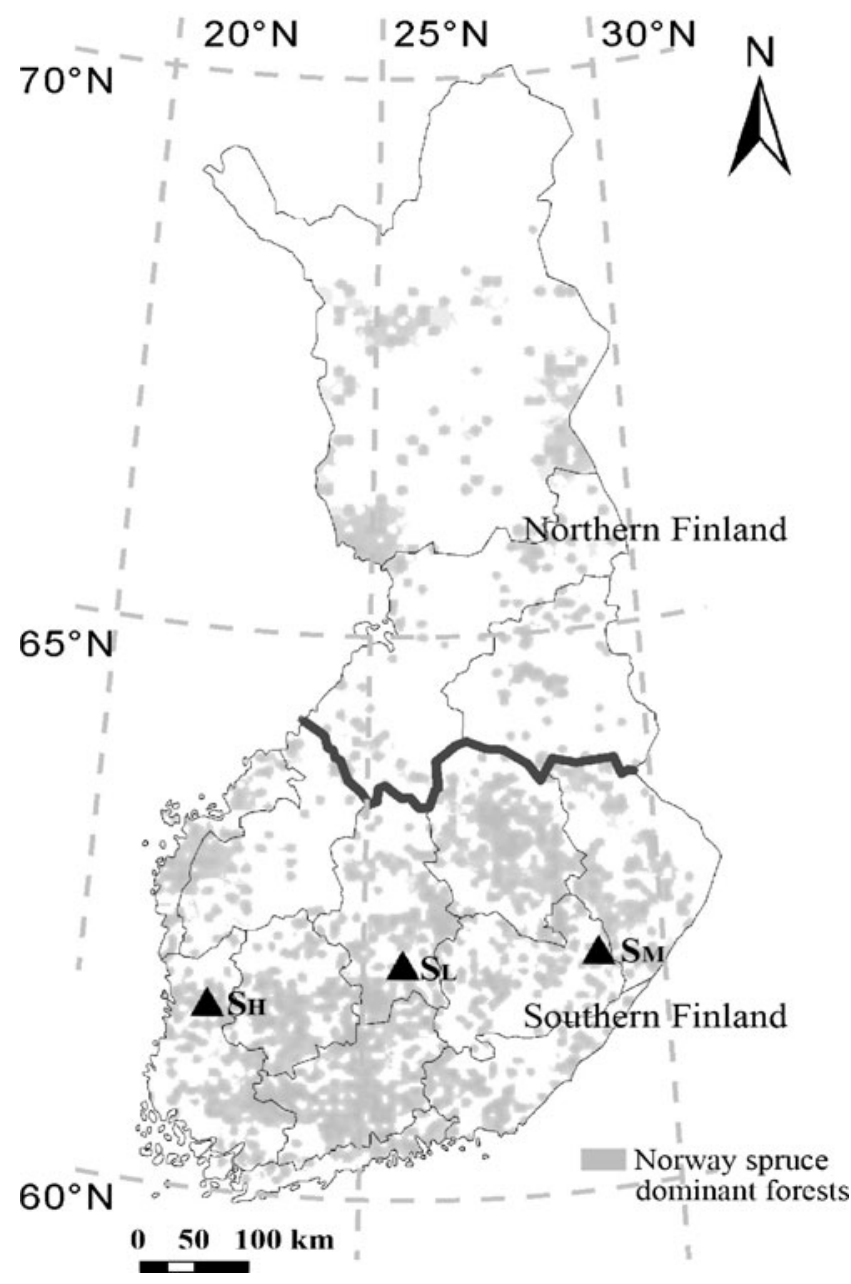

Fig. 3 Location of the three study sites with varying initial soil moisture conditions (ranging from high $\left(S_{\mathrm{H}}\right)$ to medium $\left(S_{\mathrm{M}}\right)$ and low $\left(S_{\mathrm{L}}\right)$ ) and distribution of Norway spruce dominated forests in southern Finland 
Table 1 General description of the stands for each site with different altitudes and soil moisture conditions

$S_{\mathrm{H}}$ representing the site with the highest, $S_{\mathrm{M}}$ the medium, and $S_{\mathrm{L}}$ the lowest initial soil moisture content

\begin{tabular}{llll}
\hline Stand layout and parameter & $S_{\mathrm{H}}$ & $S_{\mathrm{M}}$ & $S_{\mathrm{L}}$ \\
\hline NFI serial number & No. 35029231 & No. 40091231 & No. 32048131 \\
Location & $61^{\circ} 19^{\prime} \mathrm{N}, 22^{\circ} 09^{\prime} \mathrm{E}$ & $61^{\circ} 31^{\prime} \mathrm{N}, 29^{\circ} 18^{\prime} \mathrm{E}$ & $61^{\circ} 26^{\prime} \mathrm{N}, 25^{\circ} 09^{\prime} \mathrm{E}$ \\
Site type & $\mathrm{MT}$ & $\mathrm{MT}$ & $\mathrm{OMT}$ \\
Soil moisture (volume \%) & 44.07 & 40.26 & 37.31 \\
Density (trees ha & & 3,175 \\
Number of cohorts & 2,858 & 3,094 & 8 \\
Leaf area index & 5 & 9 & 1.89 \\
Mean diameter $(\mathrm{cm})$ & 1.34 & 1.63 & 7.44 \\
Mean height $(\mathrm{m})$ & 6.09 & 5.90 & 7.23 \\
\hline
\end{tabular}

in wintertime, but the increase is small in summertime (Carter et al. 2005; Ruosteenoja et al. 2005). The annual mean temperature and precipitation over the simulation period for the three sites are presented in Fig. 4, indicating that the precipitation on site $\mathrm{S}_{\mathrm{L}}$ is lower than on the other sites.

The data for the current and changing climate was given in terms of daily mean values considering the season shift and inter-annual variation. The values were further decomposed into hourly values by applying the weather generator developed by Kellomäki and Väisänen (1997) in order to calculate the rates of photosynthesis, respiration, and transpiration. Furthermore, the values of some weather factors not available in the FINADPT data were generated. In the simulations, the hourly values of the following weather factors were used: air temperature, $\mathrm{CO}_{2}$, precipitation, solar radiation, water vapor pressure, and wind velocity.

Selection of the thinning scenarios for analysis The concept of thinning scenario was used to indicate the sequence of thinning interventions based on the current thinning rules (Yrjölä 2002). The rules use the dominant height and basal area of trees in defining the time and intensity of thinning (Fig. 5), i.e., whenever a given upper limit for the basal area (thinning threshold) at the given dominant height is encountered, thinning is triggered. Thinning scenarios were defined in relation to the "Basic Thinning" scenario $\operatorname{BT}(0,0)$, where the zeros in the parenthesis indicate no change in the triggering and remaining basal areas. In formulating new scenarios, the values of both parameters were changes, i.e., $\mathrm{BT}( \pm n, \pm m)$, where $n$ indicates the percentage increase/decrease in the thinning threshold and $m$ the percentage increase/decrease in remaining basal area (Fig. 5).

The timing of thinning was adjusted to the growth and dynamics of the tree population in such a way that thinning from below was executed whenever the triggering combination of dominant height and basal occurred. This adjustment excludes the natural mortality between consecutive interventions, but trees could still die before the first thinning due to crowding. Throughout the rotation, a small
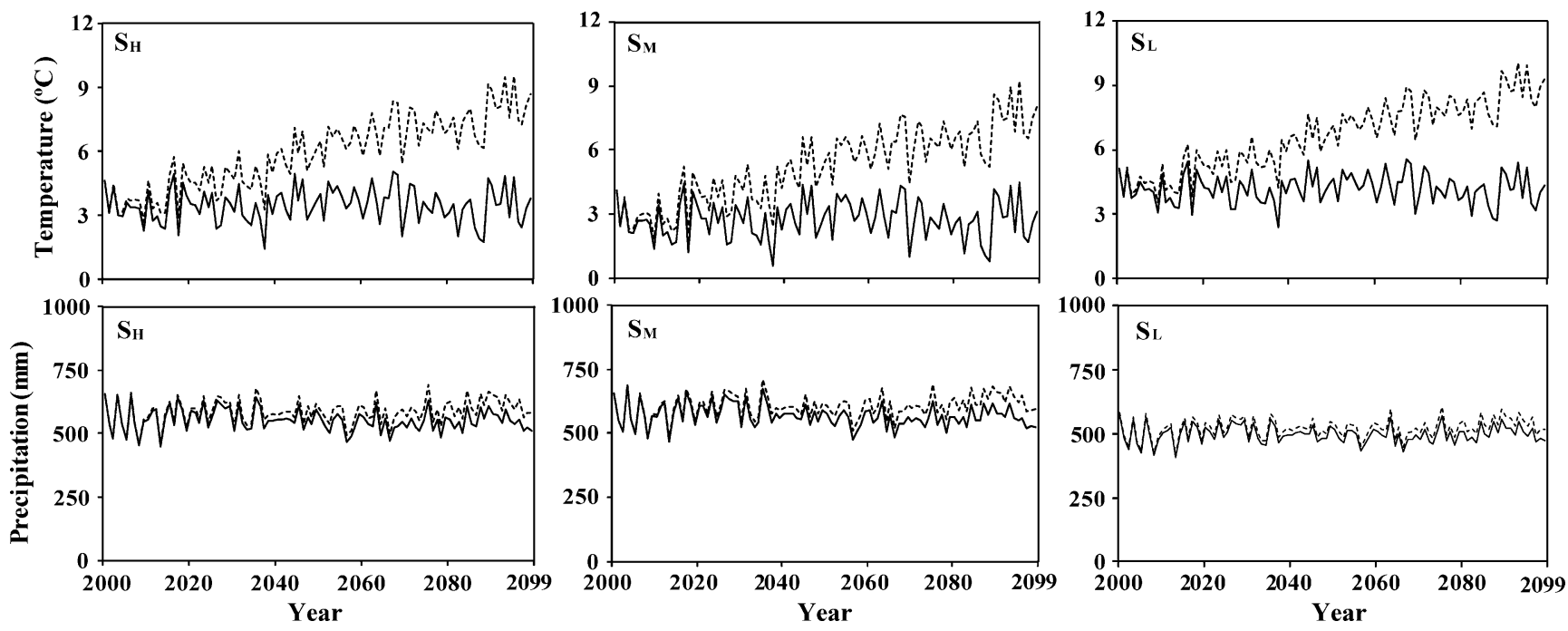

Fig. 4 Annual variation in mean annual temperature (upper panel) and precipitation (bottom panel) for the current (solid line) and changing (dashed line) climate for the $S_{\mathrm{H}}, S_{\mathrm{M}}$, and $S_{\mathrm{L}}$ sites 
Fig. 5 Principles used to define the proper thinning scenarios for final analyses with the help of the development of dominant height and basal area. The examples of $-15 \%$ change of upper threshold and $+15 \%$ change of lower threshold for the thinning regimes are expressed as dashed lines

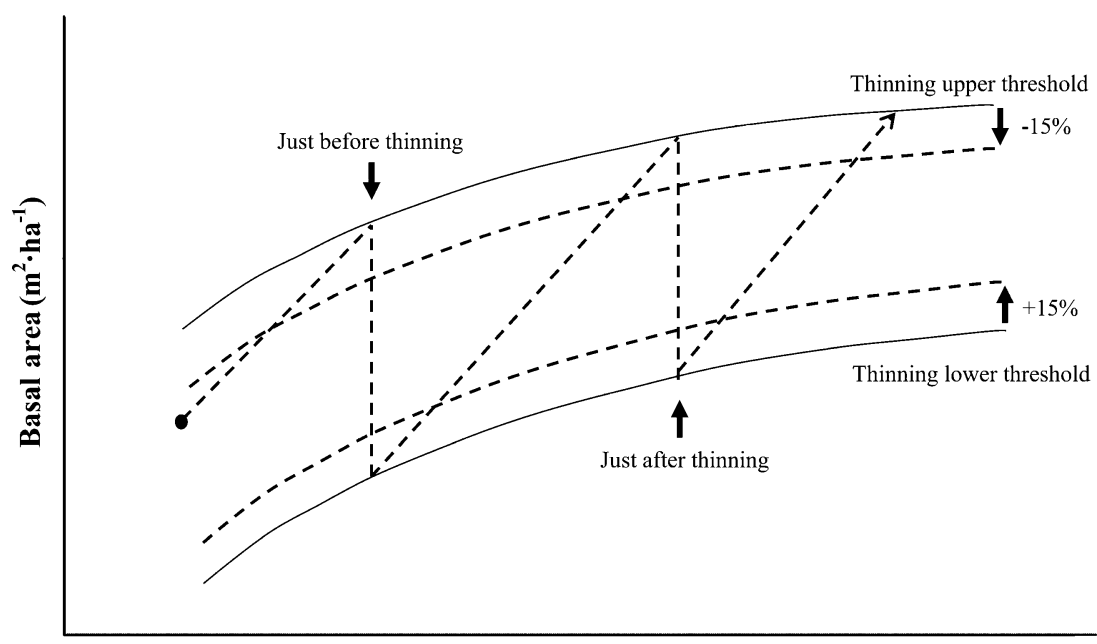

Dominant height (m) amount of trees died randomly, even though the mortality due to crowding was excluded between different thinnings and final cut (Hynynen et al. 2002).

The values of the triggering and remaining basal area may be combined in many ways. Based on the work of Briceño-Elizondo et al. (2006), 13 thinning scenarios (including $\mathrm{BT}(0,0)$ ) were created by varying the triggering and remaining basal area by $0 \%, \pm 15 \%$, and $\pm 30 \%$. When testing the candidates, the scenarios $\mathrm{BT}(+30,0)$ and $\mathrm{BT}$ $(+30,+30)$ yielded no thinning due to the design with too high basal area top trigger thinning. In the case of the scenarios $\mathrm{BT}(-30,0)$ and $\operatorname{BT}(0,+30)$, the difference between the triggering and remaining basal areas were too narrow to provide reasonable thinning scenarios. The remaining nine thinning scenarios were used in the analysis (Table 2). Furthermore, a scenario with no thinning was included in the analysis. The simulations were extended over the rotation of 100 years (2000-2099).

Analyses of the results Based on the simulations, the performance of the following variables were studied: (a) the sensitivity of net carbon uptake and total stem wood growth to the changing climate under no thinning; (b) the effects of thinning scenario on the net carbon uptake, total growth of stem wood, and timber yield under the changing climate; and (c) the effects of thinning scenarios and changing climate on the availability of soil water.

\section{Results}

3.1 Sensitivity of net carbon uptake and growth of stem wood to the changing climate without management

Under the current climate, the net carbon uptake tended to vary widely in Norway spruce on site $S_{\mathrm{L}}$ with the lowest initial soil moisture unlike on sites $S_{\mathrm{H}}$ and $S_{\mathrm{M}}$ with higher soil moisture (Fig. 6). When the changing climate was applied the carbon uptake increased on sites $S_{\mathrm{H}}$ and $S_{\mathrm{M}}$ up to year 40 (since start of simulation), but thereafter it decreased. At the end of the 100-year simulation period, the

Table 2 Forest management scenarios used in the study

\begin{tabular}{ll}
\hline Thinning scenario & Description of thinning regime \\
\hline $\mathrm{BT}(0,0)$ & $\begin{array}{c}\text { Basic thinning (see Fig. } 5) \text {, with upper limit }(0) \text { before and lower limit }(0) \text { of basal area after } \\
\text { thinning equal to those currently recommended to use } \\
\text { Upper limit of basal area is decreased by } 15 \% \text {; the lower limit is kept as in BT }(0,0)\end{array}$ \\
$\mathrm{BT}(-15,0)$ & $\begin{array}{l}\text { Upper limit of basal area is kept as in BT }(0,0) \text {; the lower limit is decreased by } 15 \% \\
\mathrm{BT}(0,-15)\end{array}$ \\
$\mathrm{BT}(-15,-15)$ & Upper limit of basal area is decreased by $15 \%$; the lower limit is decreased by $15 \%$ \\
$\mathrm{BT}(+15,0)$ & Upper limit of basal area increased by $15 \%$; the lower limit is kept as in $\mathrm{BT}(0,0)$ \\
$\mathrm{BT}(0,+15)$ & Upper limit of basal area is kept as in BT $(0,0)$; the lower limit is increased by $15 \%$ \\
$\mathrm{BT}(+15,+15)$ & Upper limit of basal area is kept as in $\mathrm{BT}(0,0)$; the lower limit is decreased by $30 \%$ \\
$\mathrm{BT}(0,-30)$ & Upper limit of basal area is decreased by $30 \%$; the lower limit is decreased by $30 \%$ \\
$\mathrm{BT}(-30,-30)$ &
\end{tabular}



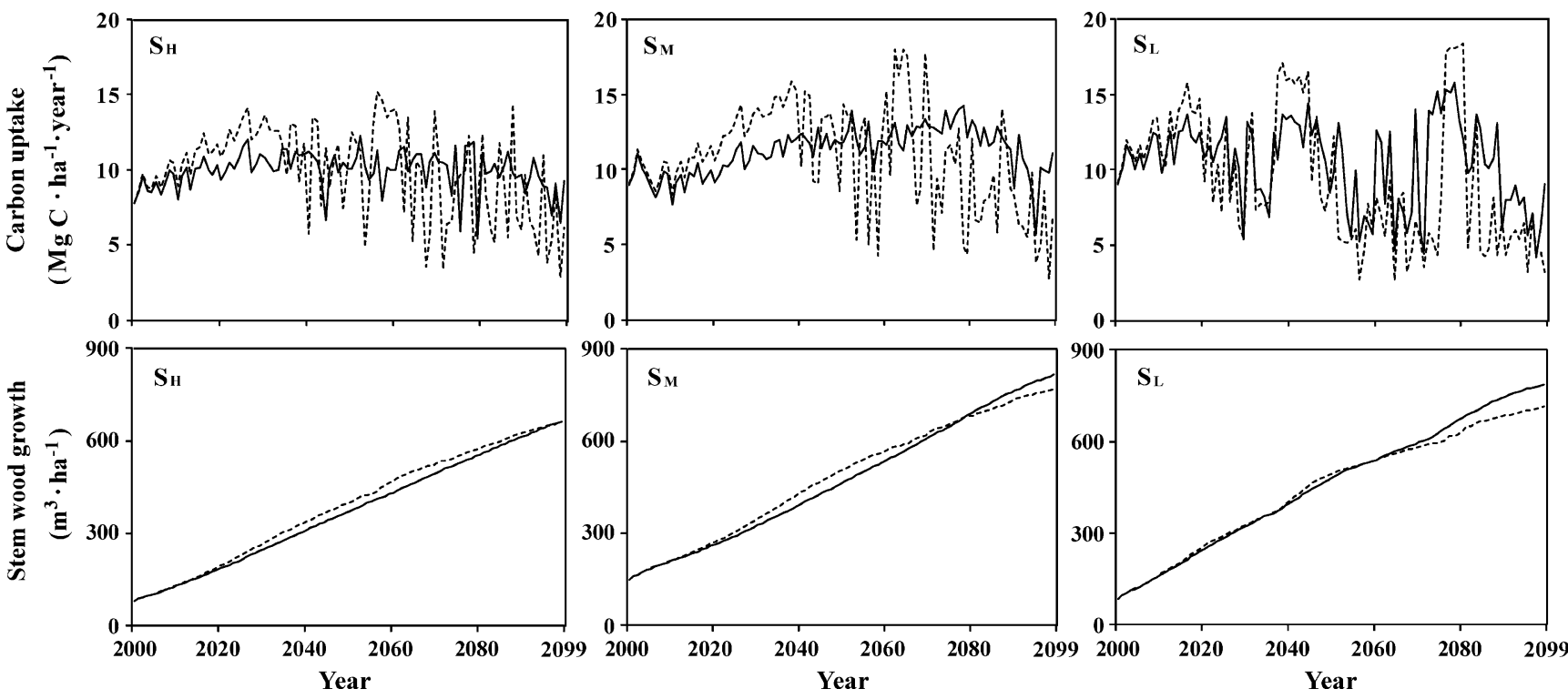

Fig. 6 Annual total carbon uptake (upper panel) and total stem wood growth (bottom panel) without management (unthinned regime) on the three sites with different initial soil moisture conditions, ranging from

cumulative carbon uptake was $1-3 \%$ lower under the changing climate than under the current climate on sites $S_{\mathrm{H}}$ and $S_{\mathrm{M}}$. On site $S_{\mathrm{L}}$, the corresponding reduction in carbon uptake was much larger, i.e., about $11 \%$.

Under the changing climate, the growth of stem wood remained slightly higher on site $S_{\mathrm{H}}$ during most of the rotation compared to that under the current climate. Also on site $S_{\mathrm{M}}$, the changing climate increased the growth, especially in the middle of the rotation, but decreased it towards the end of the rotation. On site $S_{\mathrm{L}}$, there was no clear difference in the growth between the current and changing climate during the first 60 years. Thereafter, the growth remained lower under the changing climate during the remainder of the rotation. At the end of rotation, the growth of stem wood on sites $S_{\mathrm{H}}, S_{\mathrm{M}}$, and $S_{\mathrm{L}}$ was $1 \%, 6 \%$, and $10 \%$ lower under the changing climate than under the current one, respectively.

When no thinning was applied, less water infiltrated into the soil profile under the changing climate than under the high $\left(S_{\mathrm{H}}\right)$ to medium $\left(S_{\mathrm{M}}\right)$ and low $\left(S_{\mathrm{L}}\right)$. Solid line means current climate (Cur, unthinned) and dashed line means changing climate (CC, unthinned)

current climate (Table 3). Similarly, the soil water deficit was higher in the changing climate case, especially on the site $\mathrm{S}_{\mathrm{L}}$. The cumulative water use efficiency was higher under the changing climate than under the current climate, but lower on site $S_{\mathrm{L}}$ than on the other sites.

3.2 Effects of thinning scenarios on the net carbon uptake, total growth of stem wood, and timber yield under the changing climate

Under the current climate, the alternative thinning scenarios deviated from each other mostly in the frequency of interventions and in the timing of the first thinning (Table 4). For example, the basic thinning scenario (BT $(0$, $0)$ ) included two interventions during the rotation, regardless of the site, whereas the scenarios $\mathrm{BT}(-15,0)$ and $\mathrm{BT}(0,+15)$ had three interventions. The scenarios $\mathrm{BT}(0,-15)$ and $\mathrm{BT}(0,-30)$ included only one late intervention over the rotation as did $\mathrm{BT}(+15,0)$ and $\mathrm{BT}(+15,+15)$.

simulation period under the current (Cur-UT) and changing (CC-UT) climate without thinning regime
Table 3 Comparison of the cumulative water infiltration into the soil, soil water deficit, and water use efficiency (the ratio between net photosynthesis and transpiration) on the three sites over the 100 -year

\begin{tabular}{|c|c|c|c|c|c|c|}
\hline \multirow[t]{2}{*}{ Sites } & \multicolumn{2}{|c|}{ Water infiltration to the soil $\left(\mathrm{mm} \cdot \mathrm{ha}^{-1}\right)$} & \multicolumn{2}{|c|}{ Soil water deficit $\left(\mathrm{mm} \cdot \mathrm{ha}^{-1}\right)$} & \multicolumn{2}{|c|}{ Water use efficiency $\left(\mathrm{Kg} \mathrm{C} \cdot \mathrm{mm}^{-1} \cdot \mathrm{ha}^{-1}\right)$} \\
\hline & Cur-UT & CC-UT & Cur-UT & CC-UT & Cur-UT & CC-UT \\
\hline$S_{\mathrm{H}}$ & 27,168 & 22,994 & 131 & 559 & 37 & 42 \\
\hline$S_{\mathrm{M}}$ & 26,365 & 22,657 & 208 & 669 & 41 & 48 \\
\hline$S_{\mathrm{L}}$ & 20,674 & 17,480 & 508 & 974 & 54 & 52 \\
\hline
\end{tabular}

$S_{\mathrm{H}}$ represents the site with the highest, $S_{\mathrm{M}}$ the medium, and $S_{\mathrm{L}}$ the lowest initial soil moisture content 
Table 4 Thinning frequencies for different management scenarios and sites $\left(S_{\mathrm{H}}\right.$ representing the site with the highest, $S_{\mathrm{M}}$ the medium, and $S_{\mathrm{L}}$ the lowest initial soil moisture content) under changing climate during the 100-year simulation period, not including final cutting

\begin{tabular}{|c|c|c|c|c|c|c|}
\hline \multirow[t]{2}{*}{ Management scenarios } & \multicolumn{2}{|l|}{$S_{\mathrm{H}}$} & \multicolumn{2}{|l|}{$S_{\mathrm{M}}$} & \multicolumn{2}{|l|}{$S_{\mathrm{L}}$} \\
\hline & Year of cuts & Cut frequency & Year of cuts & Cut frequency & Year of cuts & Cut frequency \\
\hline $\mathrm{BT}(0,0)$ & $50-85$ & 2 & $55-92$ & 2 & $49-82$ & 2 \\
\hline $\mathrm{BT}(-15,0)$ & $43-63-80$ & 3 & $47-69-95$ & 3 & $38-65-84$ & 3 \\
\hline $\mathrm{BT}(0,-15)$ & 54 & 1 & 56 & 1 & 54 & 1 \\
\hline $\mathrm{BT}(-15,-15)$ & $44-83$ & 2 & $49-90$ & 2 & $41-81$ & 2 \\
\hline $\mathrm{BT}(+15,0)$ & 75 & 1 & 77 & 1 & 75 & 1 \\
\hline $\mathrm{BT}(0,+15)$ & $50-65-82$ & 3 & $52-68-85$ & 3 & $48-67-83$ & 3 \\
\hline $\mathrm{BT}(+15,+15)$ & 70 & 1 & 72 & 1 & 73 & 1 \\
\hline $\mathrm{BT}(0,-30)$ & 52 & 1 & 52 & 1 & 50 & 1 \\
\hline $\mathrm{BT}(-30,-30)$ & $34-78$ & 2 & $37-80$ & 2 & $31-77$ & 2 \\
\hline
\end{tabular}

Under the changing climate, the carbon uptake was 2.4$2.7 \%$ higher for the thinning scenarios $\mathrm{BT}(+15,0)$ and $\mathrm{BT}$ $(+15,+15)$ than for the basic scenario $(\mathrm{BT}(0,0)$; Fig. 7 , upper panel) on sites $S_{\mathrm{H}}$ and $S_{\mathrm{M}}$. The carbon uptake was also enhanced for the thinning scenarios $\mathrm{BT}(-15,0)$ and $\mathrm{BT}(0,+15)$, i.e., being $1.3-1.8 \%$ higher compared to that for the basic scenario $\mathrm{BT}(0,0)$. On site $S_{\mathrm{L}}$, the carbon uptake was the highest for the scenarios BT $(-15,0)$ and BT $(0,+15)$. Similarly, it was also higher for the scenarios BT $(0,0)$ and $\mathrm{BT}(-15,-15)$ compared to $\mathrm{BT}(+15,0)$ and $\mathrm{BT}$ $(+15,+15)$.

As expected, the varying thinning scenarios variously affected the growth of stem wood (Fig. 7, bottom panel).
On sites $S_{\mathrm{H}}$ and $S_{\mathrm{M}}$, the scenarios BT $(-15,0), \mathrm{BT}(0,+15)$, $\mathrm{BT}(+15,0)$, and $\mathrm{BT}(+15,+15)$ gave the highest growth, which was also the case for the total net carbon uptake. On site $S_{\mathrm{L}}$, the growth was the highest for the scenarios $\mathrm{BT}(0,-15), \mathrm{BT}(0,+15), \mathrm{BT}(0,0)$, and $\mathrm{BT}(-15,-15)$. Regardless of the sites, the scenario BT $(-30,-30)$ gave the lowest growth of stem wood and carbon uptake. Compared to the basic thinning scenario $(\mathrm{BT}(0,0))$, the growth was $2-4.8 \%$ higher on sites $S_{\mathrm{H}}$ and $S_{\mathrm{M}}$ for the scenarios $\mathrm{BT}(+15,0)$ and $\mathrm{BT}(+15,+15)$. Similarly, the scenarios $\mathrm{BT}(-15,0)$ and $\mathrm{BT}(0,+15)$ increased the growth by $1.5-3.7 \%$ compared to BT $(0,0)$ on sites $S_{\mathrm{H}}$ and $S_{\mathrm{M}}$. On site $S_{\mathrm{L}}$, the growth was similar $(0.3-0.7 \%$ difference) for

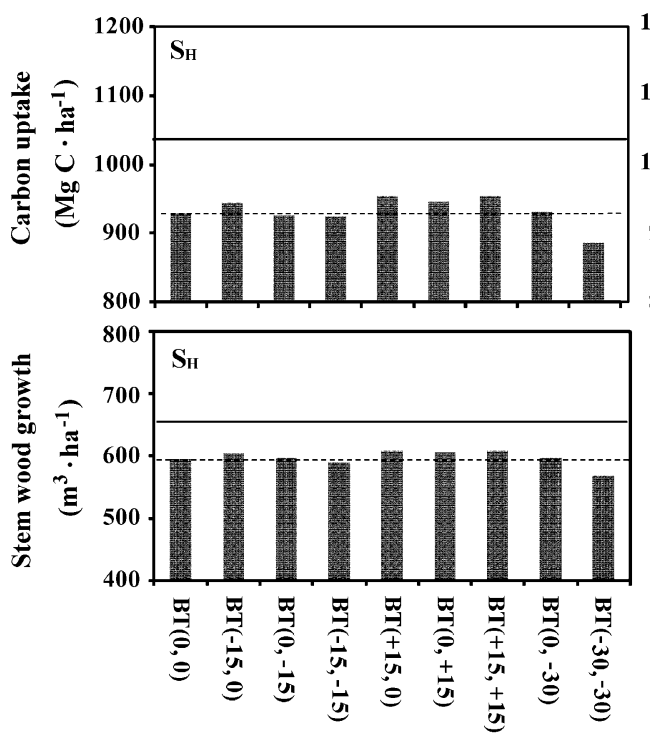

Thinning regimes

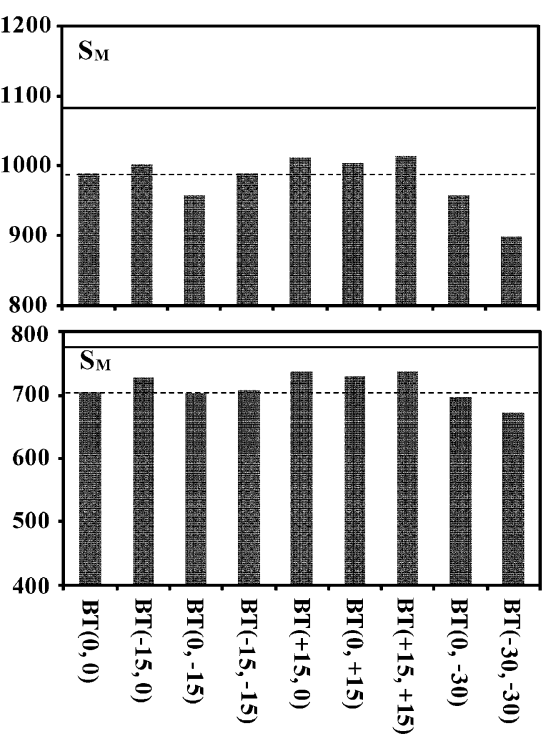

Thinning regimes

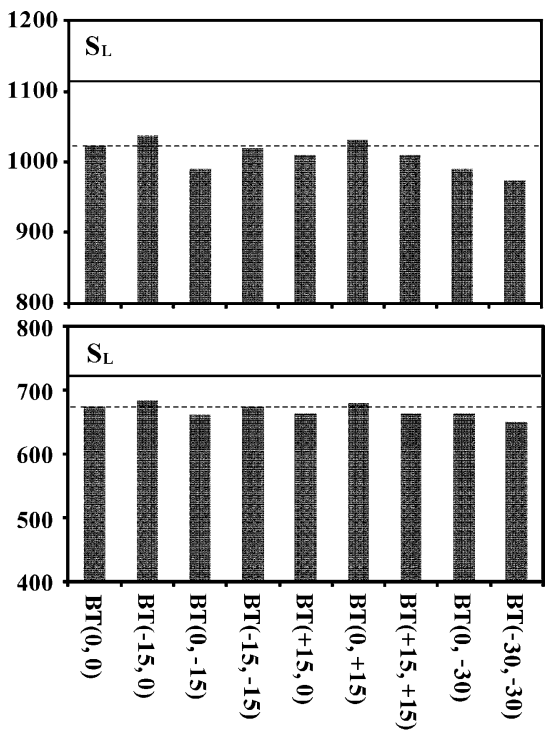

Thinning regimes
Fig. 7 Effects of varying thinning scenarios (see Table 2) on the cumulative carbon uptake (upper panel) and total stem wood growth (bottom panel) on the three sites with varying initial soil moisture conditions (ranging from high $\left(S_{\mathrm{H}}\right)$ to medium $\left(S_{\mathrm{M}}\right)$ and low $\left(S_{\mathrm{L}}\right)$ ) under the changing climate over the 100 -year period. The horizontal solid and dashed lines are the values of no thinning and currently applied thinning scenario $\operatorname{BT}(0,0)$ under the changing climate, respectively 
Table 5 Timber yield for different thinning scenarios under the changing climate $(\mathrm{CC})$, including final cutting

\begin{tabular}{llll}
\hline Management Scenarios & \multicolumn{3}{l}{ Timber $\left(\mathrm{m}^{3} \cdot \mathrm{ha}^{-1}\right)$} \\
\cline { 2 - 4 } & $S_{\mathrm{H}}$ & $S_{\mathrm{M}}$ & $S_{\mathrm{L}}$ \\
\hline UT & 482 & 603 & 515 \\
BT $(0,0)$ & 581 & 638 & 629 \\
BT $(-15,0)$ & 608 & 724 & 651 \\
BT $(0,-15)$ & 525 & 627 & 604 \\
BT $(-15,-15)$ & 577 & 634 & 620 \\
BT $(+15,0)$ & 529 & 609 & 577 \\
BT $(0,+15)$ & 602 & 716 & 650 \\
BT $(+15,+15)$ & 529 & 606 & 539 \\
BT $(0,-30)$ & 545 & 595 & 577 \\
BT $(-30,-30)$ & 501 & 591 & 528 \\
\hline
\end{tabular}

$S_{\mathrm{H}}$ represents the site with the highest, $S_{\mathrm{M}}$ the medium, and $S_{\mathrm{L}}$ the lowest initial soil moisture content

the scenarios $\mathrm{BT}(-15,0)$ and $\mathrm{BT}(0,+15)$ and the basic scenario $\mathrm{BT}(0,0)$. Under the other thinning scenarios, the growth was lower than under the basic scenario $(\mathrm{BT}(0,0))$.

In general, management scenarios with frequent thinning, such as scenarios $\mathrm{BT}(-15,0)$ and $\mathrm{BT}(0,+15)$, yielded more timber than scenarios with less frequent thinning (Table 5) over the rotation, regardless of the site. On the other hand, the growth of stem wood was positively related to the total net carbon uptake over the rotation regardless of both the thinning scenario and site (Fig. 8).

\subsection{Effects of management and changing climate on availability of soil water}

Thinning increased water infiltration in the soil profile, and thus, reduced the soil water deficit compared to the situation with no thinning (Fig. 9). The thinning scenarios $\mathrm{BT}(-15,0)$ and $\mathrm{BT}(0,+15)$ with three thinnings over the rotation increased the infiltration of water into the soil the most, with consequent reduction in the soil water deficit. When applying the basic thinning $(\mathrm{BT}(0,0))$ with two interventions, the soil moisture deficit was also reduced, but less than in the previous case. Similarly, the thinning scenarios BT $(+15,0)$ and $\mathrm{BT}(+15,+15)$, with one thinning over the rotation, slightly reduced the soil water deficit.

\section{Discussion and conclusion}

This study was implemented under the assumption that the growth of Norway spruce may be reduced under the changing climate due to the decreasing availability of soil water and that the impact is dependent on the thinning scenarios and site conditions. This claim is supported by the most recent climate change scenarios, which show only a small increase in future summer precipitation in Finland. This is likely to not meet the enhanced evaporation as a result of the forecasted higher temperatures. Consequently, the frequency of drought episodes is likely to increase, even though the winter precipitation may increase (Carter et al. 2005; Ruosteenoja et al. 2005). In this context, we assumed that the negative effects of drought episodes could be reduced by modifying the current thinning recommendations in order to reduce the evaporation losses and thus to increase water flow into the soil profile.

According to our results, the climate change is likely to increase the carbon uptake and growth of Norway spruce in southern Finland in the next few decades. This result is in line with previous model predictions, which were based on a gap-type model (Kellomäki et al. 2008b). The increase is related to earlier and more rapid recovery of photosynthetic capacity in spring and the prolongation of photosynthetic active season in autumn. However, during the latter part of the simulation period, the evaporation from canopy surfaces and the ground increased to such an extent that less water will infiltrate into the soil profile with a resulting increase in drought periods and reduction in the carbon uptake and growth. Our findings are supported by the previous longterm field experiments for Norway spruce in southern and central Sweden (see Roberntz and Stockfors 1998; Bergh et al. 1999; Phillips et al. 2001).

Under the changing climate, the occurrence of summer droughts is further enhanced by the reduced snow accumulation and early snow melt, which reduces the replenishment of soil water in spring time (Kellomäki and Väisänen 1996). Furthermore, water runoff is expected to increase considerably due to rapid snowmelt under warmer climate (see Silander et al. 2006), thereby reducing the availability of soil water. The decrease in soil moisture also negatively

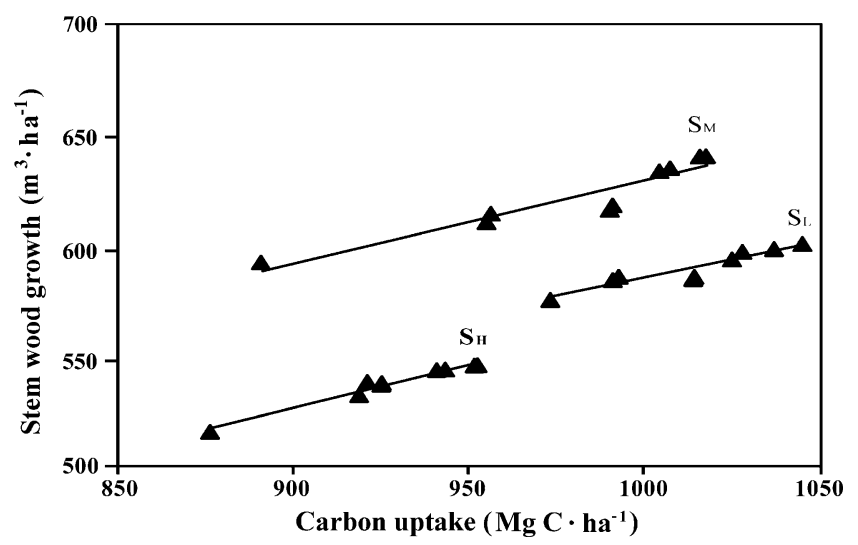

Fig. 8 Total stem wood growth as a function of the net carbon uptake for the three sites over all nine thinning scenarios. $S_{\mathrm{H}}: y=0.598 x-$ $10.433\left(R^{2}=0.968\right), S_{\mathrm{M}}: y=0.568 x+56.363\left(R^{2}=0.888\right), S_{\mathrm{L}}: y=0.494 x$ $+69.679\left(R^{2}=0.883\right) . S_{\mathrm{H}}$ represents the site with the highest, $S_{\mathrm{M}}$ the medium, and $S_{\mathrm{L}}$ the lowest initial soil moisture content 
Fig. 9 Comparison of the cumulative water infiltration into the soil (upper panel) and soil water deficit (bottom panel) on the three sites over the 100-year simulation period under the changing $(\mathrm{CC}$, unthinned) climate (first bar series) with five selected thinning scenarios (see Table 2) under the changing climate (last five bar series). $S_{\mathrm{H}}$ represents the site with the highest, $S_{\mathrm{M}}$ the medium, and $S_{\mathrm{L}}$ the lowest initial soil moisture content

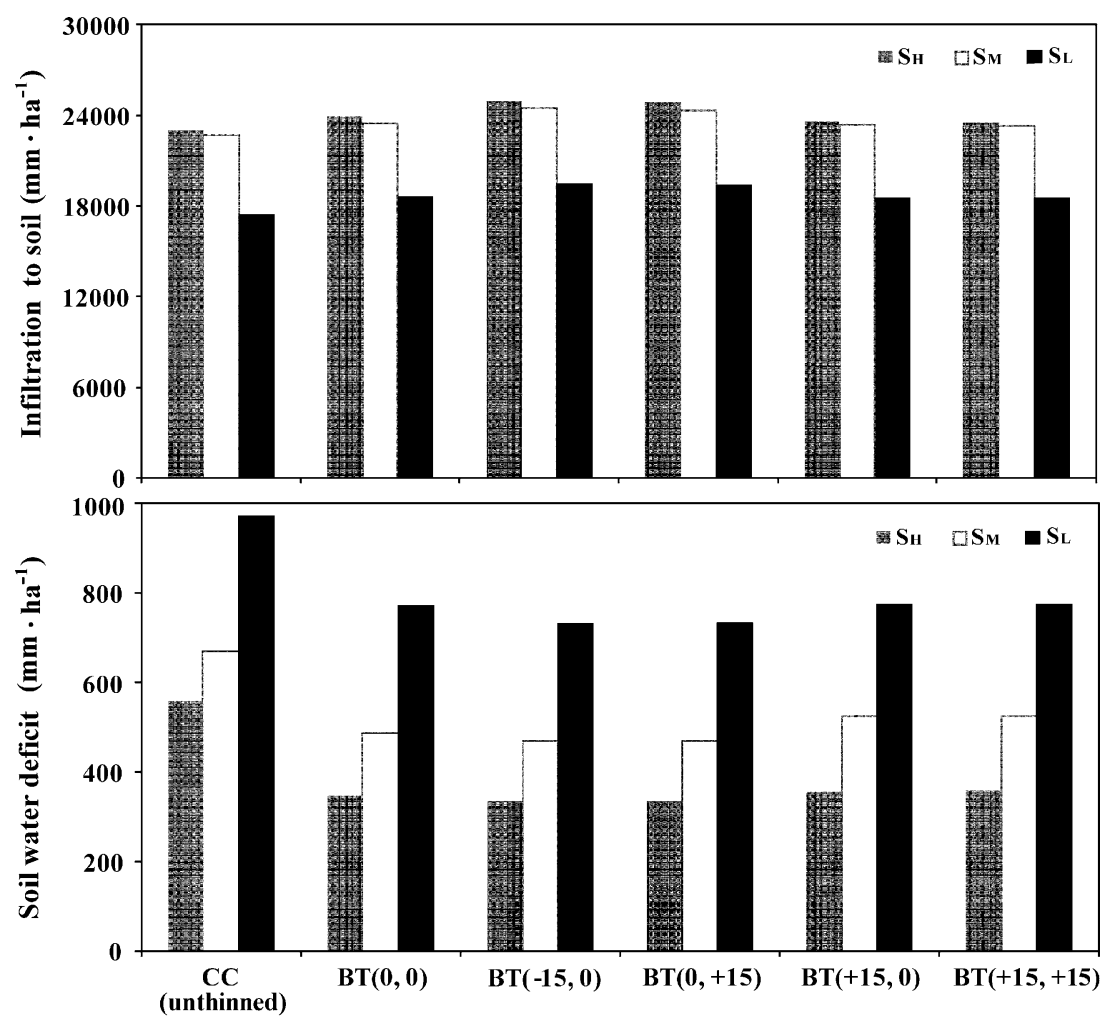

Thinning regimes affects the nitrogen uptake by the trees, consequently decreasing the growth of Norway spruce under the changing climate (see Ge et al. 2010).

The vulnerability of Norway spruce to the climate change is further enhanced by large leaf area index and large leaf-to-sapwood ratio (Waring et al. 1982; Whitehead et al. 1984), which maintain high water interception and potential water consumption (transpiration) under the elevated temperature. However, the impacts of the reduced soil water on the carbon uptake and growth may partly be compensated by the increasing water use efficiency as found to occur in conifers under elevated $\mathrm{CO}_{2}$ (cf. Kellomäki and Wang 1998). This increase is partly related to changes in stomatal functions and partly due to the increase in supply of $\mathrm{CO}_{2}$. This held also in our simulation study, which showed an increase of $12-15 \%$ in the water use efficiency on sites $S_{\mathrm{H}}$ and $S_{\mathrm{M}}$ under the changing climate (Table 3 ).

In our work, the various thinning scenarios adopted deviated from each other mainly in terms of the number and intensity of the thinnings and the timing of the first thinning (Table 4). Regardless of the site, the management with frequent thinnings yielded more timber than management with less frequent or heavy thinnings (Table 5). This pattern is related to the mean stocking, which was larger in the former case over the rotation. On the other hand, the thinning increased water infiltration into the soil profile and thus, reduced the soil water deficit compared to the situation with no thinning (Fig. 9). Furthermore, the infiltration of water into the soil increased if the mean spacing was kept wider throughout the rotation with less evaporative losses from the canopy than in other cases.

A proper thinning scenario (timing, intensity, and frequency of interventions) seems to mitigate the harmful effects which the climate change may have on the growth of Norway spruce due to evaporative losses of water. Previously, Kellomäki et al. (2008a) have demonstrated, for central European conditions, that the wider spacing and regular thinning may increase the water yield by $15-20 \%$ over the rotation when there is reduced evaporation from canopy surfaces.

In this context, different ecosystem services such as timber yield and carbon stock in the forest ecosystems should also be taken into account. On the sites with high soil water availability, the thinning scenarios with moderate intensive thinning $(\mathrm{BT}(-15,0)$ and $\mathrm{BT}(0,+15))$ and/or scenarios with delayed first thinning $(\mathrm{BT}(+15,0 /+15))$ may simultaneously provide higher stem wood growth and carbon stock in stocking (Fig. 7), opposite to the scenarios with earlier heavy thinnings such as BT $(-30,-30)$, where the mean stocking is low. Regarding the sites with poor soil water availability, the thinning scenarios with moderate 
intensive thinning may be useful for soil water deficit mitigation, leading to even higher timber yield (Fig. 9, Table 5).

Based on our findings, there is evident need to modify the current thinning guidelines for Norway spruce in order to adapt the Norway spruce forests to the climate change in southern Finland. Among the key questions is how to fully consider the region- and site-specific differences regarding water supply for growth and carbon sequestration in the forest ecosystem.

Acknowledgments This work was funded through the Finland Distinguished Professor Programme (FiDiPro; 2008-2012) of the Academy of Finland (127299-A5060-06) coordinated by Prof. Seppo Kellomäki and Prof. Kai-Yun Wang, University of Eastern Finland, School of Forest Sciences. Dr. David Gritten is greatly thanked for revising the language of this paper. Two anonymous reviewers were greatly appreciated for their constructive criticism and comments on a previous version.

\section{References}

Bergh J, Linder S, Lundmark T, Elfving B (1999) The effect of water and nutrient availability on the productivity of Norway spruce in northern and southern Sweden. For Ecol Manage 119:51-62

Bergh J, Linder S, Bergström J (2005) Potential production of Norway spruce in Sweden. For Ecol Manage 204:1-10

Briceño-Elizondo E, Garcia-Gonzalo J, Peltola H, Matala J, Kellomäki S (2006) Sensitivity of growth of Scots pine, Norway spruce and silver birch to climate change and forest management in boreal conditions. For Ecol Manage 232:152-167

Cajander AK (1949) Metsätyypit ja niiden merkitys. Acta Forestalia Fennica 56:5-6

Carter TR, Jylhä K, Perrels A, Fronzek S, Kankaanpää S (2005) FINADAPT scenarios for the 21st century: alternative futures for considering adaptation to climate change in Finland. FINADAPT Working Paper 2, Finnish Environmental Institute Mimeographs. Helsinki

Chertov OG, Komarov AS (1997) SOMM - a model of soil organic matter dynamics. Ecol Model 94:177-189

Cienciala E, Kucera J, Ryan MG, Lindroth A (1998) Water flux in boreal forest during two hydrologically contrasting years; species specific regulation of canopy conductance and transpiration. Ann For Sci 55:47-61

Farquhar GD, von Caemmerer S, Berry JA (1980) A biochemical model of photosynthetic assimilation in leaves of $\mathrm{C}_{3}$ species. Planta 149:67-90

Ge ZM, Zhou X, Kellomäki S, Wang KY, Peltola H, Väisänen H, Strandman H (2010) Effects of changing climate on water and nitrogen availability with implications on the productivity of Norway spruce stands in southern Finland. Ecol Model 221:1731-1743

Granier A, Bréda N, Biron P, Villette S (1999) A lumped water balance model to evaluate duration and intensity of drought constraints in forest stands. Ecol Model 116:269-283

Hänninen H, Hari P (2002) Recovery of photosynthesis of boreal conifers during spring: a comparison of two models. For Ecol Manage 169:53-64

Hynynen J, Ojansuu R, Hökkä H, Salminen H, Siipilehto J, Haapala P (2002) Models for predicting stand development in MELA System. Finn For Res Inst Res Pap 835:1-116

Jansson PE (1991a) Soil model user's manual. Sveriges Lantbruksuniversitet. Uppsala Avdelningsmeddelande 91(7):1-59
Jansson PE (1991b) Simulation model for soil water and heat conditions. Description of the soil model. Sveriges Lantbruksuniversitet. Uppsala Rapp 165:1-72

Kellomäki S, Väisänen H (1996) Model computations on the effect of rising temperature on soil moisture and water availability in forest ecosystems dominated by Scots pine in the boreal zone in Finland. Clim Change 32:423-445

Kellomäki S, Väisänen H (1997) Modelling the dynamics of the forest ecosystem for climate change studies in the boreal conditions. Ecol Model 97:121-140

Kellomäki S, Wang KY (1997) Effects of long-term $\mathrm{CO}_{2}$ and temperature elevation on crown nitrogen distribution and daily photosynthetic performance of Scots pine. For Ecol Manage 99:309-326

Kellomäki S, Wang KY (1998) Sap flow in Scots pines growing under conditions of year-round carbon dioxide enrichment and temperature elevation. Plant Cell Environ 21:969-981

Kellomäki S, Wang KY (1999) Short-term environmental controls of heat and water vapour fluxes above a boreal coniferous forestmodel computations compared with measurements by eddy correlation. Ecol Model 124:145-173

Kellomäki S, Wang KY (2000) Modelling and measuring transpiration from Scots Pine with increased temperature and carbon dioxide enrichment. Ann Bot 85:263-278

Kellomäki S, Peltola H, Ryyppö A (2008a) Implications and consequences. In: Kahle HP et al (eds) Causes and consequences of forest growth trends in Europe. European Forest Institute. Brill, Leiden-Boston, pp 238-253

Kellomäki S, Peltola H, Nuutinen T, Korhonen KT, Strandman H (2008b) Sensitivity of managed boreal forests in Finland to climate change, with implications for adaptive management. Philos Trans R Soc B 363:2339-2349

Lu P, Biron P, Breda N, Granier A (1995) Water relations of adult Norway spruce (Picea abies (L.) Karst) under soil drought in the Vosges mountains: water potential, stomatal conductance and transpiration. Ann For Sci 52:117-129

Lu P, Biron P, Granier A, Cochard H (1996) Water relations of adult Norway spruce (Picea abies (L.) Karst) under soil drought in the Vosges mountains: whole-tree hydraulic conductance, xylem embolism and water loss regulation. Ann For Sci 53:113-121

Mäkelä A, Landsberg J, Ek AR, Burk TE, Ter-Mikaelian M, Ågren GI, Oliver CD, Ja PP (2000) Process-based models for forest ecosystem management: current state of the art and challenges for practical implementations. Tree Physiol 20:289-298

Marklund LG (1987) Biomass functions for Norway spruce (Picea Abies (L.) Karst) in Sweden. Swedish University of Agricultural Sciences. Department of Forest Survey. Report 43:1-127

Matala J, Hynynen J, Miina J, Ojansuu R, Peltola H, Sievänen R, Väisänen H, Kellomäki S (2003) Comparison of a physiological model and a statistical model for prediction of growth and yield in boreal forests. Ecol Model 161:95-116

Matala J, Ojansuu R, Peltola H, Sievänen R, Kellomäki S (2005) Introducing effects of temperature and $\mathrm{CO}_{2}$ elevation on tree growth into a statistical growth and yield model. Ecol Model 181:173-190

Medlyn BE, Barton CVM, Broadmedow MSJ, Ceulemans R, Dangeles P, Forstreuter M, Freeman M, Jackson SB, Kellomäki S, Laitat E, Rey A, Roberntz P, Sigurdsson BD, Strassemeyer J, Wang KY, Curtis PS, Jarvis PG (2001) Stomatal conductance of forest species after long-term exposure to elevated $\mathrm{CO}_{2}$ concentrations: a synthesis. New Phytol 149:247-264

Medlyn BE, Dreyer E, Ellsworth D, Forstreuter M, Harley PC, Kirschbaum MUF, Le Roux X, Montpied P, Stassenmeyer J, Walcroft A, Wang KY, Loustau D (2002) Temperature response of parameters of a biochemically based model of photosynthesis. II. A review of experimental data. Plant Cell Environ 25:1167-1179

Monteith JL, Unsworth MH (1990) Principles of environmental physics, 2nd edn. Edward Arnold, New York, 291 pp 
Phillips N, Bergh J, Oren R, Linder S (2001) Effects of nutrition and soil water availability on water use in a Norway spruce stand. Tree Physiol 21:851-860

Reineke LH (1933) Perfecting a stand-density index for evenaged forests. J Agric Res 46:627-638

Roberntz P, Stockfors J (1998) Effects of elevated $\mathrm{CO}_{2}$ concentration and nutrition on net photosynthesis, stomatal conductance and needle respiration of field-grown Norway spruce trees. Tree Physiol 18:233-241

Ruosteenoja K, Jylhä K, Tuomenvirta H (2005) Climate scenarios for FINADAPT studies of climate change adaptation. FINADAPT Working Paper 15, Finnish Environmental Institute. Mimeographs, Helsinki

Silander J, Vehviläinen B, Niemi J, Arosilta A, Dubrovin T, Jormola J, Keskisarja V, Keto A, Lepistö A, Mäkinen R, Ollila M, Pajula H, Pitkänen H, Sammalkorpi I, Suomalainen M, Veijalainen N (2006) Climate change adaptation for hydrology and water resources. FINADAPT Working Paper
6, Finnish Environment Institute Mimeographs 336, Helsinki, $52 \mathrm{pp}$

Thornley JHM, Cannell MGR (2000) Managing forests for wood yield and carbon storage: a theoretical study. Tree Physiol 20:477-484

Vehviläinen B, Huttunen M (2002) The Finnish watershed simulation and forecasting system (WSFS). Publication of the 21st conference of Danube countries on the hydro-logical forecasting and hydrological bases of water management

Waring RH, Schroeder PE, Oren R (1982) Application of the pipe model theory to predict canopy leaf area. Can J For Res 12:556560

Whitehead D, Edwards WRN, Jarvis PG (1984) Conducting sapwood area, foliage area, and permeability in mature trees of Picea sitchensis and Pinus contorta. Can J For Res 14:940-947

Yrjölä T (2002) Forest management guidelines and practices in Finland, Sweden and Norway. Internal Report 11. European Forest Institute, pp. 1-46 